\begin{tabular}{|c|c|}
\hline Title & A study on the effectiveness of microwave heating for disinfection of humidifier elements \\
\hline Author(s) & Kang, Y oonkyung; Kato, Shinsuke \\
\hline Citation & $\begin{array}{l}\text { Hvac\& r research, 20(1), } 113-120 \\
\text { https://doi.org/10.1080/10789669.2013.834780 }\end{array}$ \\
\hline Issue Date & 2014-01-01 \\
\hline Doc URL & http:/hdl.handle.net/2115/57638 \\
\hline Rights & $\begin{array}{l}\text { This is an A ccepted Manuscript of an article published by Taylor \& Francis in HV AC\&R Research on 1,January 2014, } \\
\text { avail lable online: http://www.tandfonline.com/10.1080/10789669.2013.834780. }\end{array}$ \\
\hline Type & article (author version) \\
\hline File Information & Kang Y K_full Manuscripts_HV A C\&R Research (2014) 20, 113-120.pdf \\
\hline
\end{tabular}

Instructions for use 


\title{
A study on the effectiveness of microwave heating for disinfection of humidifier elements
}

\author{
Yoonkyung Kang, ${ }^{1 *}$, Shinsuke Kato ${ }^{2}$ \\ 1 Faculty of Engineering, Hokkaido University, Hokkaido, Japan \\ 2 Institute of Industrial Science, The University of Tokyo, Tokyo, Japan \\ *Correspondence author. E-mail: phycology99@gmail.com
}

In this study, microwave irradiation was tested as a possible means to disinfect evaporative humidifiers in air-conditioning systems. A mock-up of a humidifier was prepared to identify the applicability of the microwave irradiation system. To characterize the heating properties of this system under optimum operating conditions, the temperature distribution of the humidifier element was measured as a function of various parameters. Variables included the use of ventilation and water spraying during microwave irradiation, the level of radiation output power and whether the element was dry or wet. The results showed that microwave irradiation can heat the evaporative humidifier element about $60^{\circ} \mathrm{C}$ at 1200 W for exposure times greater than 3 minutes under non-operating conditions (without air blower and water spraying). However, the temperature distribution of the element was non-uniform, regardless of whether the conditions were dry or wet. The effectiveness of microwave heating is limited due to non-uniform distribution of temperature. To achieve a uniform surface temperature on the element, further studies are necessary.

\section{Introduction}

Humidifiers have been used to maintain a comfortable indoor environment and to prevent respiratory symptoms from worsening due to extremely low humidity (Green 1985, Arundel et al. 1986). Humidifier types include steam vaporizers, atomizing humidifiers and evaporative humidifiers, and they are used with heating, ventilating, and air-conditioning (HVAC) systems (EPA 2007). Steam vaporizer humidifiers create steam by heating water. It is hygienic way, but it requires a large amount of energy to heat the water. Atomizing humidifiers use a high-speed disk that sprays water through a fine comb to create a mist that is introduced directly into the airstream, where it evaporates. Atomizing humidifiers consumes less energy than that of steam vaporizer humidifiers. However, it should be noticed that the emitted mist might be 
contaminated by microorganisms. (Shaw et al. 1991, Alvarez-Fernández et al. 1998). Evaporative humidifiers invisibly transmit moisture into the air using a fan to blow air through elements. Evaporative humidifiers consume less energy and are a hygienic way of humidifying, as there are no aerosol sprays being released.

Therefore, evaporative humidifiers are widely used in buildings. However, evaporative humidifiers still have several problems, such as microbial contamination on surfaces of humidifier elements. Because the elements are usually moist while under operation, microbial contamination can occur when the air stream blows through a contaminated filter (Burge et al. 1980, Strindehag et al. 1991, Tyndall et al. 1995, Shimotsu et al. 2010). For this reason, this study focuses on disinfecting the evaporative humidifier element. The microbes that grow on the humidifier element surface can become airborne and be transported throughout an entire building's air-conditioning systems (Marinkovich and Hii 1975, Katsui et al. 1995).

There have been efforts to resolve this problem using ultraviolet germicidal irradiation (UVGI) in the evaporative humidifier element (Sung et al. 2011). However, UVGI inactivates only the element surface of the humidifier and does not penetrate into the element. Low-frequency microwave radiation is a better tool for disinfection. Microwave radiation penetrates deep into the component, heating it directly, rapidly and selectively. These characteristics motivated our efforts to find a feasible way to perform microwavemediated disinfection of air conditioning systems.

In our previous study (Kang and Kato 2013), we investigated the germicidal effect of microwave irradiation on fungal spores (e.g., Cladosporium herbarum and Fusarium solani), vegetative bacteria and bacterial spores (e.g., Bacillus subtilis) on the filter. We determined that the germicidal effect originates directly from the radiation-induced temperature increase of the buffer $(0.9 \% \mathrm{NaCl}$ solution). We reported that microwave disinfection occurred due to a temperature increase (heating effect) of the liquid sample. The germicidal effect of our strains was shown at liquid suspension temperatures above $60^{\circ} \mathrm{C}$ except for the B. subtilis spores.

Some researchers has been studied on the disinfection temperature of bacteria by microwave. Woo et al. (2000) reported that the viable counts of bacteria B. subilis or Escherichia coli were reduced dramatically decreased in the liquid buffer when the microwave heating temperature exceeded $60^{\circ} \mathrm{C}$. Stout et al. (1986) measured that the ranges of thermal death times of the family Legionellaceae in the liquid 
broth at $60^{\circ} \mathrm{C}, 70^{\circ} \mathrm{C}$, and $80^{\circ} \mathrm{C}$ were $1.3 \mathrm{~min}$ to $10.6 \mathrm{~min}, 0.7 \mathrm{~min}$ to $2.6 \mathrm{~min}$, and $0.3 \mathrm{~min}$ to $0.7 \mathrm{~min}$, respectively. Goldblith and Wang (1967) showed that microwave cause no destruction of E. coli in the buffer when held below $51{ }^{\circ} \mathrm{C}$. Therefore, we assumed that the minimum temperature for thermal disinfection is $60^{\circ} \mathrm{C}$ except for the microorganisms resistant to heat. In this study, the practicability of microwave heating the humidifier elements above $60^{\circ} \mathrm{C}$ investigates by a mock-up system. This article describes (1) manufacturing the mock-up humidifier (2) identifying the optimum mode for microwave heating, and (3) determining of microwave intensity inside the humidifier cavity.

\section{Methods}

\section{System setup}

To determine the practicability of microwave irradiation in disinfecting humidifier elements, a mockup humidifier unit was manufactured. The experimental setup is composed of three parts: a microwave generator, an evaporative humidifier and an air blower (Figure 1). The air stream, driven by an exhaust blower fan, enters and exits the system through a high-efficiency particulate air (HEPA) filter. The water stream was supplied from a water tank to the element using a water pump (Figure 2). The microwave source (model IMH-20A259, IDX Inc., Japan) had variable output power ranging from 1 to $1,500 \mathrm{~W}$ at frequencies of $2,455 \pm 30 \mathrm{MHz}$.

To prevent the leakage of microwave power, microwave shields were installed between the duct and the humidifier. The microwave shields were perforated plates with a hole diameter and thickness of $1.0 \mathrm{~mm}$ (Figure 3-b). The humidifier, duct parts and microwave shields were made with stainless steel. The cavity volume and surface area between the microwave shields of the humidifier was $0.112 \mathrm{~m}^{3}$ and $1.692 \mathrm{~m}^{2}$, respectively. The evaporative humidifier element had a honeycomb structure and was constructed from non-inflammable material with dimensions of $300(\mathrm{~W}) \times 300(\mathrm{~L}) \times 100(\mathrm{D}) \mathrm{mm}^{3}$.

Microwave leakage from the contact surface of joint for humidifier mock-up was determined using an electro smog meter (TES-92, TES Electrical Electronic Corp, Taiwan). The microwave intensity from outside the mock-up humidifier was 1/10 of the International Commission on Non-Ionizing Radiation Protection (ICNIRP 1998) standard for public areas, $10 \mathrm{~W} / \mathrm{m}^{2}$. 


\section{Measurement I : Temperature and distribution of elements by microwave}

To determine the optimum conditions for microwave heating, the following items were considered: (1) the temperature of the element during operation/nonoperation of the process of ventilation and spraying water during irradiation, (2) the temperature of the element at different output powers, (3) the temperature distribution of the element in dry or wet conditions, and (4) the temperature distribution based on the thickness of the elements.

Considerations for the microwave heating method include safety, the germicidal effect and energy consumption. Thus, the irradiation method needs to consider the temperature of the evaporative humidifier element during the operating mode and non-operating modes of the HVAC system. The HVAC system operates according to a schedule, these conditions affected microwave disinfection. Therefore, to decide whether to continue ventilation and water spraying during microwave irradiation, we determined the temperature of the element surfaces under the operating mode (continuous and simultaneous ventilation and water spraying) and under the non-operating mode (with the element wet) during irradiation at 1,200 W. During the operating mode condition, the air blower was operated at an air flow rate of $29.1 \mathrm{~m}^{3} / \mathrm{min}$, and the water pump was operated at a water flow rate of $0.48 \sim 0.52 \mathrm{~L} / \mathrm{min}$. We assessed the temperature behavior of the humidifier unit under various conditions. An optical fiber thermometer (Neoptix, Reflex ${ }^{\mathrm{TM}}$, Canada) was used to take measurements at two points: at the center of both the front (facing the microwave generator) and rear faces of the humidifier under a one-piece, $100 \mathrm{~mm}$ thick wet element (Figure 3-a).

To identify temperature increases above $60^{\circ} \mathrm{C}$, the temperature of the element were measured at seven microwave power levels: 450, 600, 750, 900, 1,050, 1,200 and 1,350 W. The exposure time was five minutes, which was sufficient to counteract the temperature of the dry element without water spraying and ventilation.

Usually, an evaporative humidifier element is wetted while under operation. Therefore, in addition to measurements on a dry element, we also conducted experiments under wet conditions in non-operating mode. The temperature distribution of the element was measured from the outside of the microwave shield with an infrared camera (Fluke Ti25, Fluke Corp., USA) when irradiated at 1,200 W for five minutes (Figure 3-b, c). 
To confirm whether to disinfect the element, in the case of thicker elements, we measured the temperature and the temperature distribution of the two-piece element surface in the dry condition at 1,200 W. Figure 4 shows the temperature measurement points: the center of the front, between of elements and the rear faces of the humidifier. The experiments were performed three times in all cases.

\section{Measurement II : Distribution of microwave intensity inside the humidifier cavity}

The microwave density was analyzed inside the humidifier using the following approaches: (1) measurement of the microwave density at distance from the waveguide, (2) correlation between the microwave density and the humidifier shape, and (3) measurement of the absorbed power in the element.

We conducted three experiments under different conditions: no element present (Case 1), a one-piece element (Case 2), and a two-piece element (Case 3). We used a dry element without ventilation or water spraying. The microwave density in the cavity between microwave shields was measured as the water temperature increased by irradiation in these three cases. This test method was modified from the IEC 705 (1988) method for household microwave ovens.

Fifty milliliters of distilled water was poured into $100 \mathrm{ml}$ beakers that were placed at the front and rear of the element. Figure 5 shows the temperature measurement locations from point 1 to point 8 . The temperature of the distilled water was detected by an optical fiber thermometer sensor under microwave irradiation at $1,200 \mathrm{~W}$ for one minute. Then, the increase in the water temperature was measured. To measure the power of the absorbed radiation in the element, we compared the microwave density at the contact points $(3,4,5,6)$ and non-contact points $(1,2,7,8)$ of the elements. These measurement points are symmetric with respect to the duct-axis. The power absorbed by the water was measured at the contact points and non-contact points of elements. The value of the power absorbed in the distilled water was calculated by the following equation (1):

$$
\mathrm{P}=\mathrm{M} \times \mathrm{C} \times\left(\mathrm{T}_{\mathrm{b}}-\mathrm{T}_{\mathrm{a}}\right) / \mathrm{t}
$$

where $\mathrm{P}$ is the microwave power absorbed in the distilled water (W), $\mathrm{M}$ is the weight of the distilled water $(\mathrm{g}), \mathrm{C}$ is the heat capacity of the distilled water $\left(\mathrm{J} / \mathrm{g}{ }^{\circ} \mathrm{C}\right), \mathrm{T}_{\mathrm{a}}$ and $\mathrm{T}_{\mathrm{b}}$ are the temperatures of the distilled water before and after irradiation $\left({ }^{\circ} \mathrm{C}\right)$ and $\mathrm{t}$ is the irradiation time $(\mathrm{sec})$. The experiments were performed three times in all cases. 


\section{Results}

\section{Temperature and distribution of elements by microwave}

Figure 6 shows how ventilation and water spraying affect the temperature changes caused by irradiation. In the operating mode, the irradiation caused no heating, whereas in the non-operating mode, the temperature of both faces in wet condition gradually increased to approximately $55^{\circ} \mathrm{C} \sim 60^{\circ} \mathrm{C}$ when irradiated at 1,200 W for eight minutes. Figure 7 shows the temperature of the front and rear surfaces of the element when exposed to microwave irradiation at different output powers for five minutes. The results show that microwave irradiation with a higher power quickly yielded a higher temperature for the element. The temperature of the front face was higher than of the rear face. The temperature of the front and the rear face increased $33.7 \pm 0.4^{\circ} \mathrm{C}$ or $20.8 \pm 0.2^{\circ} \mathrm{C}$ respectively when exposed to $450 \mathrm{~W}$. When exposed to $1,350 \mathrm{~W}$, the temperature of the front and the rear face increased $41.1 \pm 0.6^{\circ} \mathrm{C}$ and $39.2 \pm 2.6^{\circ} \mathrm{C}$ respectively. The temperature difference between the front and the rear faces was larger when irradiated with a high output power compared to a low output power. Therefore, we considered that the high output power can heat the rear face as well as the front face. A previous study (Kang and Kato 2013) demonstrated that microwave irradiation can disinfect bacteria above a temperature limit of $60^{\circ} \mathrm{C}$. Therefore, we have to employ an output power of more than $1,200 \mathrm{~W}$; the minimum time required to heat the dry element at the front face up to $60^{\circ} \mathrm{C}$ using $1,200 \mathrm{~W}$ of irradiation is three minutes.

The temperature of the element when exposed to $1,200 \mathrm{~W}$ of irradiation for ten minutes is shown in Figures 8-a and 9-a for the dry and wet case, respectively. The temperature on both of its faces was sharply increased for three minutes, and then slowly increased in both dry and wet condition. In the dry element, the temperature on the front surface increased $39.9 \pm 1.2^{\circ} \mathrm{C}$ (from $21.2 \pm 0.9^{\circ} \mathrm{C}$ to $61.1 \pm 0.5^{\circ} \mathrm{C}$ ), and on the rear face increased $35.0 \pm 1.1^{\circ} \mathrm{C}$ (from $18.9 \pm 0.2^{\circ} \mathrm{C}$ to $53.9 \pm 1.3^{\circ} \mathrm{C}$ ) when irradiated for three minutes. After irradiation for eight minutes, the temperature of both faces became the same. In the wet element, the difference of the temperature between the front and the rear faces was large. The temperature on the front or the rear surfaces increased $51.2 \pm 0.8^{\circ} \mathrm{C}$ (from $12.1 \pm 1.0^{\circ} \mathrm{C}$ to $63.3 \pm 0.3^{\circ} \mathrm{C}$ ) and $23.7 \pm 1.0^{\circ} \mathrm{C}$ (from $10.5 \pm 0.2^{\circ} \mathrm{C}$ to $34.2 \pm 1.1^{\circ} \mathrm{C}$ ) when irradiated for three minutes. A comparison shows that on the front surface, the temperature of the wet element is higher than that of the dry element. Conversely, on the rear surface, 
the temperature of the dry element is much higher than that of the wet element. These results indicate that radiation is absorbed in the water on the front face. We assume that if microwaves continuously irradiate the wet element, they can heat the rear face of the element because the wet element is dried by irradiation. The dry sample shows a similar temperature distribution on both of its faces (Figure 8-b, c), whereas the wet sample shows a high temperature gradient (Figure 9-b, c). The temperature distribution of the element was not uniform, regardless of whether it is dry or wet.

The temperature distribution for the two-piece dry sample shown in Figure 10. The temperature of the front side was higher than that of the rear side; the temperature increased $68.3 \pm 1.2^{\circ} \mathrm{C}$ on the front side; $61.7 \pm 1.4^{\circ} \mathrm{C}$ on middle $1 ; 52.9 \pm 1.0^{\circ} \mathrm{C}$ on middle $2 ; 42.5 \pm 1.3^{\circ} \mathrm{C}$ on the rear side (Figure 10 -a). The result shows that the thicker element has a larger temperature difference between front and rear faces by microwave heating. The temperature distribution was similar on both of its faces (Figure 10-b, c). These results indicated that microwaves penetrated into the two-piece from the front to the rear side in the dry condition. We found that elements with thickness higher than $200 \mathrm{~mm}$ could not be disinfected on the rear side at 1,200 $\mathrm{W}$ for ten minutes in dry conditions. We also considered that the rear side of $200 \mathrm{~mm}$ thick wet element could not be disinfected at 1,200 W for ten minutes exposure. Therefore, the amount of irradiation should increase considerably for thicker and wet elements.

\section{Distribution of microwave intensity inside the humidifier cavity}

The prior results show that microwave heating was uneven, as evidenced by the temperature distribution on the element. To investigate the cause, we analyzed the microwave density inside the humidifier cavity.

Relationship between microwave density and distance from the waveguide The microwave power absorbed in the water and the temperature of the water are summarized in Table 1 . The microwave power absorbed by the water is considered the microwave density of the location. The microwave density shows an irregular tendency at the distance from the waveguide between the closed position (point 1,2 ) and at a distant point from the waveguide (point 7,8 ) in Case 1 (no element present).

Relationship between the microwave density and the humidifier shape. The humidifier has a symmetric structure with respect to the duct-axis, and the microwave density is generally similar at the 
symmetric locations (point 1-2, 3-4, 5-6, 7-8). The results indicated that the humidifier shape affects the intensity of the microwaves on the location of humidifier cavity. The microwave density of the measurement locations (point 1-3-5-7 and point 2-4-6-8) in the duct-axis direction is uneven. These results indicate the formation of standing waves, which affected the intensity in the humidifier cavity.

The microwave power absorbed in the element. In Case 2, using a one-piece element, the microwave density at the non-contact locations of the element (point $1,2,7,8$ ) was higher than the density at the contact locations (point 3, 4, 5, 6). In Case 3, using a two-piece element, the non-contact points (point 1,2 ) and contact points (point 3,4) of the element show similar power intensity. In our study, we were unable to measure the amount of absorbed power in the element.

\section{Discussion}

The previous study demonstrated the germicidal effect of microwaves at temperatures above $60^{\circ} \mathrm{C}$ in the liquid condition. In this study, a mock-up of a humidifier was manufactured, and we investigated the possibility of heating the evaporative humidifier element above $60^{\circ} \mathrm{C}$ by microwave irradiation. The results demonstrated that the microwave heating can occur under non-operating (without air blower and water spraying) conditions.

The temperature of one-piece dry element on the front side or rear side increased above $60^{\circ} \mathrm{C}$ at 1,200 $\mathrm{W}$ for exposure times greater than three minutes or nine minutes. In wet condition of one-piece element, the front face increased above $60^{\circ} \mathrm{C}$ whereas the rear face could not reach the same temperature because the radiation may have been absorbed by the water on the front side. We found that the wet element can heat the rear side with a sufficient irradiation time because the water on the front side will evaporate.

In two-piece element case, both faces increased above $60^{\circ} \mathrm{C}$ under dry condition. The temperature distribution of the front and rear faces was the same after five minutes of irradiation on both one- and twopiece elements. These results indicated that microwaves penetrated into the two pieces of the $100 \mathrm{~mm}$ thick element in the dry condition.

UVGI is not expected to disinfect the internal evaporative humidifier elements because UVGI is absorbed on surface of the element. The microwave irradiation is expected to disinfect the internal evaporative humidifier elements. However, the temperature distribution of the element was found to be 
non-uniform, regardless of whether it was dry or wet. The cold spots below $60^{\circ} \mathrm{C}$ are not expected to be disinfected.

To determine the cause of the non-uniform temperature distribution, we measured the microwave density inside the mock-up humidifier. The results show that the microwave density was similar at symmetric locations with respect to the duct-axis and uneven in the duct-axis direction. These results indicated that microwave density has a spatial difference, and the uneven temperature for the vertical profile may be caused by standing waves. Therefore, we demonstrated that the temperature and distribution of the element was different based on the number of elements and whether the element was dry or wet. The number of elements may have influenced the formation of standing waves. In future studies, we will investigate the pattern of standing waves. Variations of these methods that produce a uniform heating by microwave simulation should also be considered.

\section{Conclusion}

In this study, we determined the optimum conditions for microwave heating by a mock-up unit. First, we demonstrated that microwave heating can occur under non-operating conditions (without air blower and water spraying). The temperature of an element at different outputs was shown to increase faster with a high power. The temperature difference of one-piece on front side or rear side was small in dry condition. The temperature difference on front side or rear side was large with the two-piece of the dry element or one-piece of the wet element. These results indicated that the thick elements and elements with a high water content are much less penetrated by microwave radiation. The temperature distribution of the element was found to be non-uniform, regardless of whether it was dry or wet. Therefore, a second experiment determined the microwave density inside the humidifier cavity. The result showed that the microwave density is uneven at different locations. It is assumed that the effectiveness of disinfection on the element is limited. Therefore, we suggest that the temperature distribution on the element was uneven because the element was affected by microwave density in the humidifier cavity.

\section{Acknowledgements}


We appreciate suggestions by U Yanagi, M. Sung and M. Harada. This work was performed with the financial support of Tokyo Electric Power Company.

\section{References}

Alvarez - Fernández, J.A., S. Quirce, J.L. Calleja, M. Cuevas, and E. Losada. 1998. Hypersensitivity pneumonitis due to an ultrasonic humidifier. Allergy 53(2):210-212.

Arundel, A. V., E. M. Sterling, J. H. Biggin, and T. D. Sterling. 1986. Indirect health effects of relative humidity in indoor environments. Environ Health Persp 65: 351.

Burge, H. A., W. R. Solomon, and J. R. Boise. 1980. Microbial prevalence in domestic humidifiers. Appl Environ Microb 39 (4): 840-4.

EPA (2007) BASE Buildings Test Space HVAC Characteristics: Humidification System Types, Environmental Protection Agency http://www.epa.gov/iaq/base/pdfs/test_space_hvac_characteristics/thc-19.pdf

Goldblith, S. A., and D. I. C. Wang. 1967. Effect of microwaves on escherichia coli and bacillus subtilis. Appl Environ Microb 15 (6): 1371-5.

Green, G. H. 1985. Indoor relative humidities in winter and the related absenteeism. ASHRAE Transactions 91 (1): 643-53.

International Electrotechnical Commission. 1988. Methods for measuring the performance of microwave ovens for household and similar purposes. Publication 705.

International Commission on Non-Ionizing Radiation Protection. 1998. Guidelines for limiting exposure to time-varying electric, magnetic, and electromagnetic fields (up to $300 \mathrm{GHz}$ ). Health Physics 74 (4): 494-522.

Katsui, N., H. Nakata, M. Sakamoto, F. Nishikawa, and E. Kita. 1996. Experimental study on the microbial contamination of evaporating-type humidifiers. The Society of Heating, Air-Conditioning and Sanitary Engineers of Japan 61, 37-44 (in Japanese).

Kang, Y. S. Kato. 2013 Thermal and non-thermal germicidal effects of microwave radiation on microbial agents, Indoor and Built Environment (in press).

Marinkovich, V. A., and A. Hill. 1975. Hypersensitivity alveolitis. JAMA: The Journal of the American Medical Association 231 (9): 944-7.

Shaw, CY, RJ Magee, CJ Shirtliffe, and H. Unligil. 1991. Indoor air quality assessment in an office-library building: Part II-Test results. ASHRAE Transactions 97 (2): 136-45.

Shimotsu, T. Yanagi, U. Takatori, K. Yoneda, M. Harada, M. Takase, Y. and Nakabayashi, T. 2010. Study of microbial decontamination method in evaporative humidifier. Proceedings of contamination control, Tokyo, Japan, A08, pp 73-88.

Stout, J. E., M. G. Best, and V. L. Yu. 1986. Susceptibility of members of the family legionellaceae to thermal stress: Implications for heat eradication methods in water distribution systems. Appl Environ Microb 52 (2): 396-9.

Strindehag, O., I. Josefsson, and E. Henningson. 1991. Emission of bacteria from air humidifiers. Environment International 17 (4): 235-41.

Sung, M., S. Kato, U. Yanagi, M. Kim, and M. Harada. 2011. Disinfection performance of ultraviolet germicidal irradiation systems for the microbial contamination on an evaporative humidifier. HVAC\&R Research 17 (1): 22-30.

Tyndall, R. L., E. S. Lehman, E. K. Bowman, D. K. Milton, and J. M. Barbaree. 1995. Home humidifiers as a potential source of exposure to microbial pathogens, endotoxins, and allergens. Indoor Air 5 (3): $171-8$.

Woo, I. S., I. K. Rhee, and H. D. Park. 2000. Differential damage in bacterial cells by microwave radiation on the basis of cell wall structure. Appl Environ Microb 66 (5): 2243-7. 
List of tables

Table 1 Microwave density at different location inside humidifier

\begin{tabular}{|c|c|c|c|c|c|c|c|c|c|}
\hline \multicolumn{8}{|c|}{ Table 1. Microwave density at difference location inside humidifier } \\
\hline $\begin{array}{c}\text { Number of } \\
\text { element }\end{array}$ & Case & 1 & 2 & 3 & 4 & 5 & 6 & 7 & 8 \\
\hline & & \multicolumn{7}{|c|}{ Microwave power [W] } & 5 \\
\hline 0 & Case 1 & $75.5 \pm 1.4$ & $52.5 \pm 4.0$ & $118.0 \pm 2.2$ & $130.5 \pm 0.6$ & $59.8 \pm 1.4$ & $64.4 \pm 1.0$ & $175.3 \pm 5.4$ & $146.6 \pm 9.3$ \\
\hline 1 & Case 2 & $152.8 \pm 2.8$ & $144.0 \pm 2.1$ & $75.1 \pm 0.5$ & $61.1 \pm 1.0$ & $57.6 \pm 3.5$ & $39.9 \pm 1.1$ & $111.9 \pm 4.2$ & $122.3 \pm 2.3$ \\
\hline 2 & Case 3 & $98.0 \pm 3.3$ & $93.0 \pm 3.9$ & $95.8 \pm 2.3$ & $77.9 \pm 0.6$ & - & - & $42.7 \pm 3.6$ & $41.0 \pm 2.6$ \\
\hline
\end{tabular}


List of figures

Figure 1. Schematic drawing of the mock-up

Figure 2. Schematic drawing of the evaporative humidifier

Figure 3. Temperature measurement of the humidifier element: (a) an optical fiber thermometer; and (b) an infrared camera

Figure 4. Temperature measurement point of two pieces the humidifier element: (a) front view; and (b) side view

Figure 5. Measurement point of microwave density inside humidifier cavity: (a) Case 1, not installed an element; (b) Case 2, installed one-piece element; and (c) Case 3, installed two-pieces element

Figure 6. Temperature changes of the humidifier element upon irradiation: (a) under the operating mode (ventilation, water spraying); and (b) under the non-operating mode

Figure 7. Temperature of the front and rear surfaces at different microwave output powers: (a) front surface; and (b) rear surface

Figure 8. Comparison of the temperature distribution on the element surfaces in the dry condition: (a) temperature change of both surfaces measured in the center; (b) front surface; and (c) rear surface

Figure 9. Comparison of the temperature distribution on the element surfaces in the wet condition: (a) temperature change of both surfaces measured in the center; (b) front surface; and (c) rear surface

Figure 10. Comparison of the temperature distribution on the two-piece element surfaces in the dry condition: (a) temperature change of both surfaces measured in the center; (b) front surface; and (c) rear surface 
Figure 1. Schematic drawing of the mock-up set-up

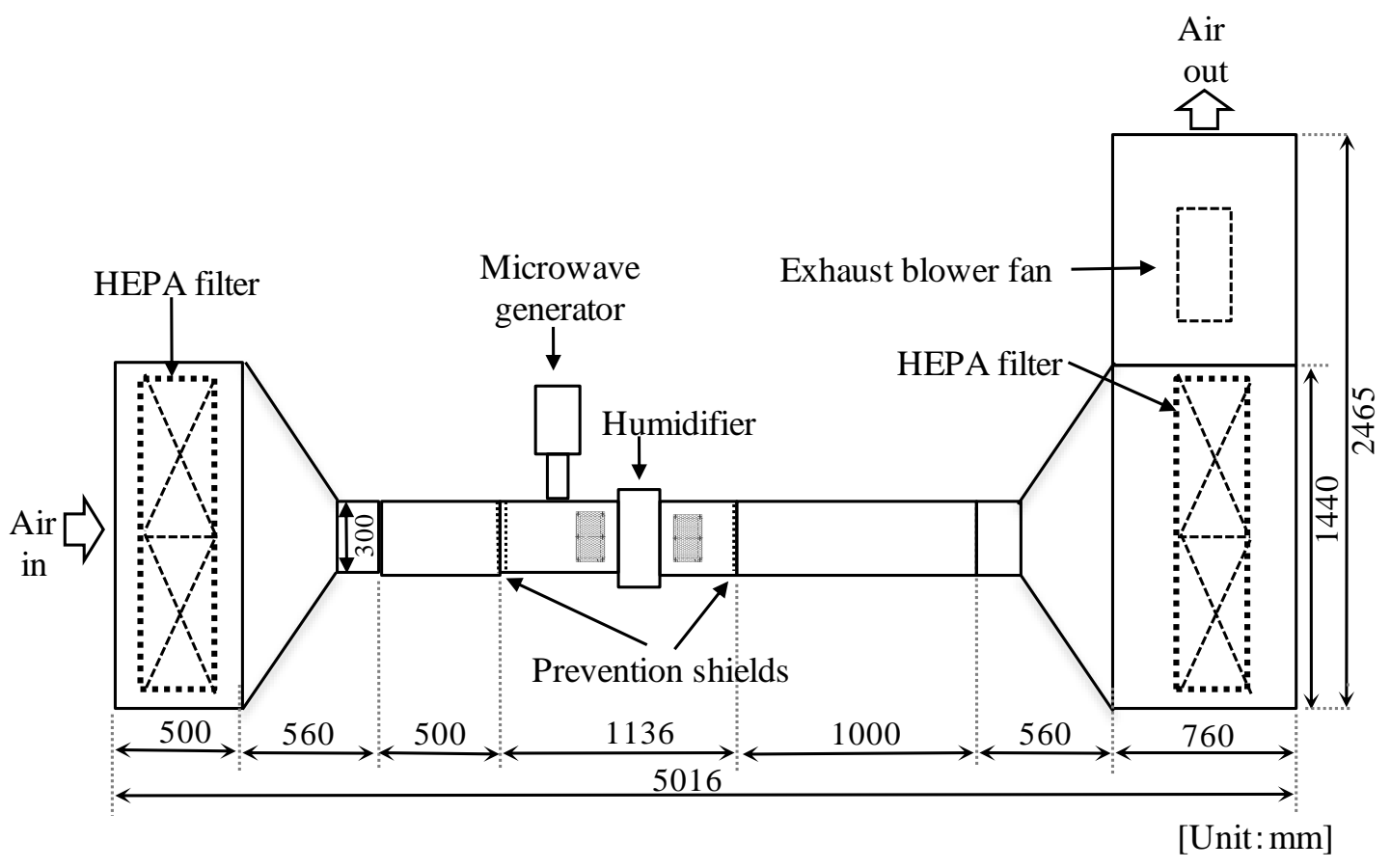


Figure 2. Schematic drawing of the evaporative humidifier

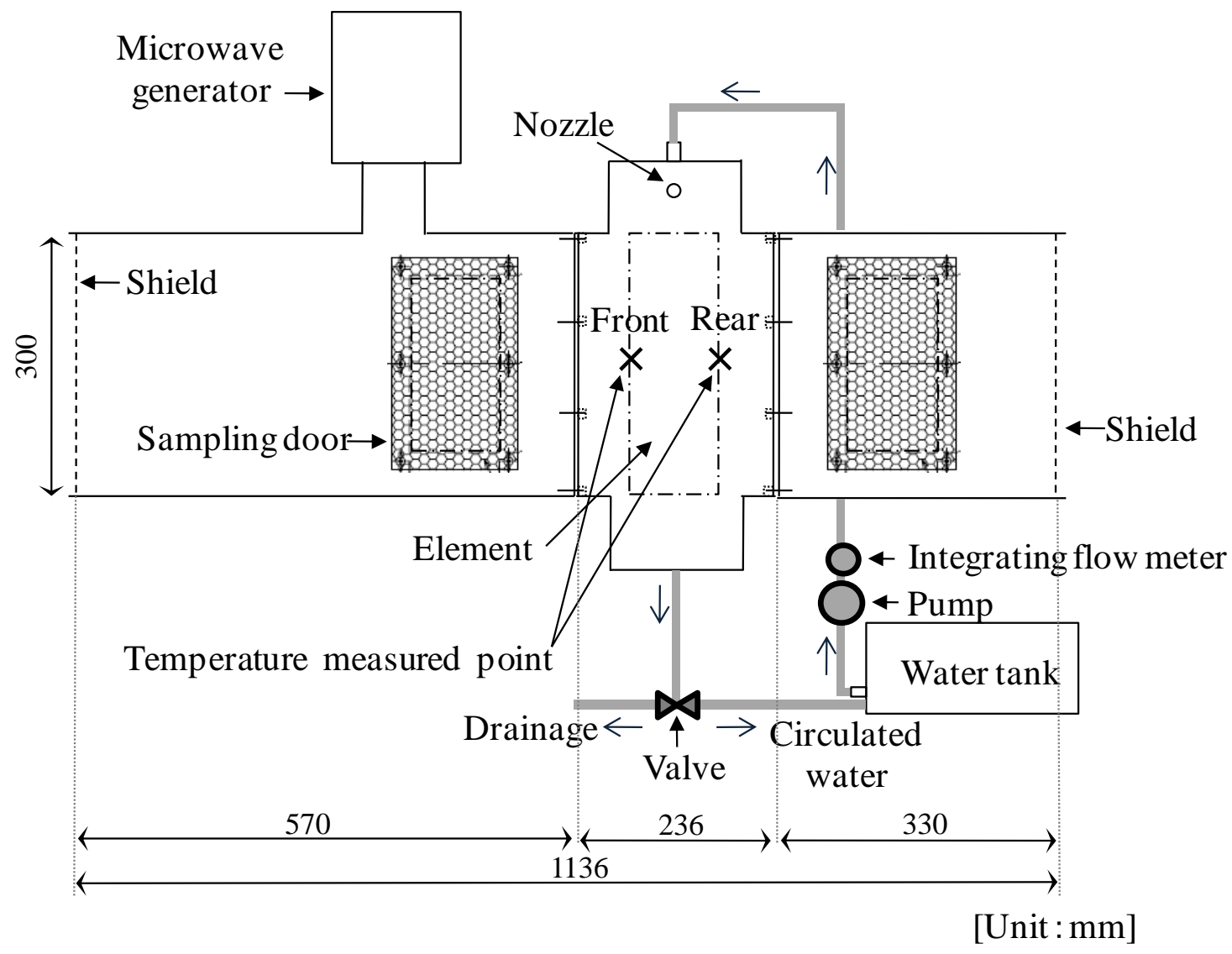


Figure 3. Temperature measurement of the humidifier element: (a) an optical fiber thermometer; (b) outside of the microwave shield; and (c) an infrared camera
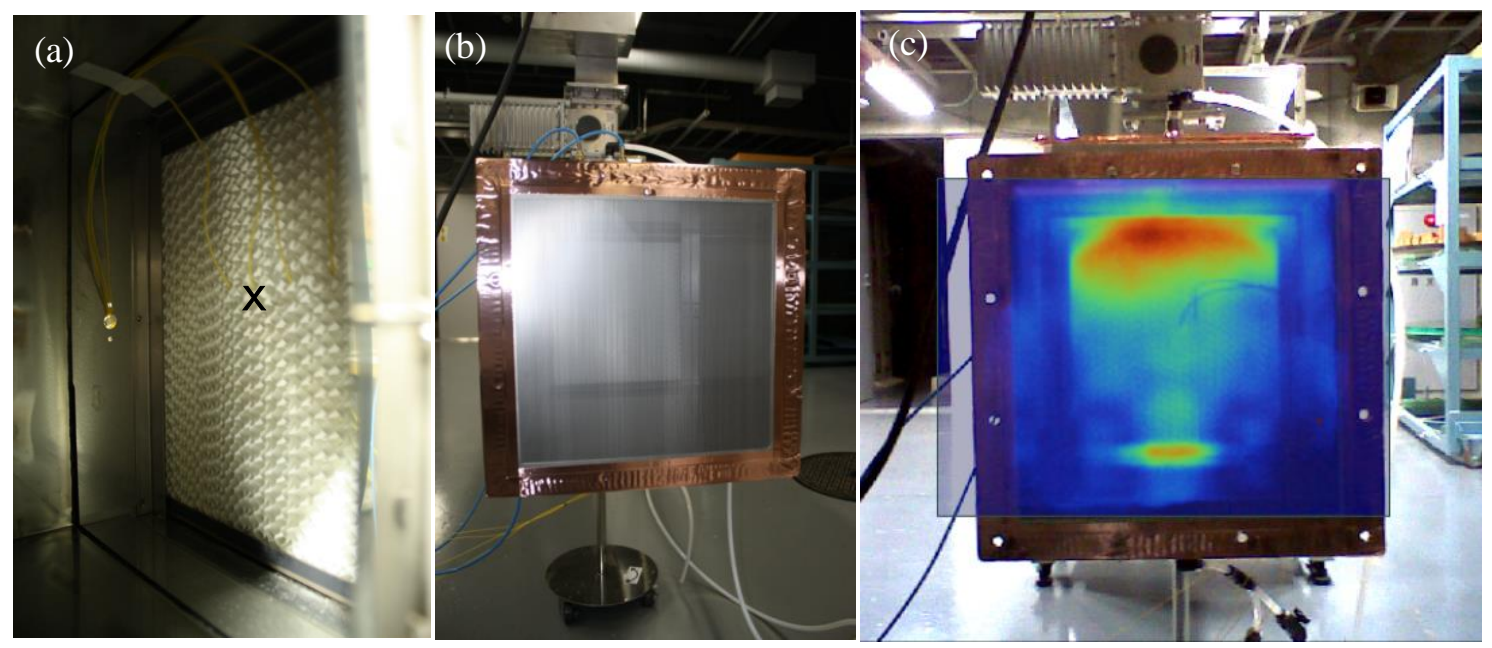
Figure 4. Temperature measurement point of two pieces the humidifier element: (a) front view; and (b) side view

(a)

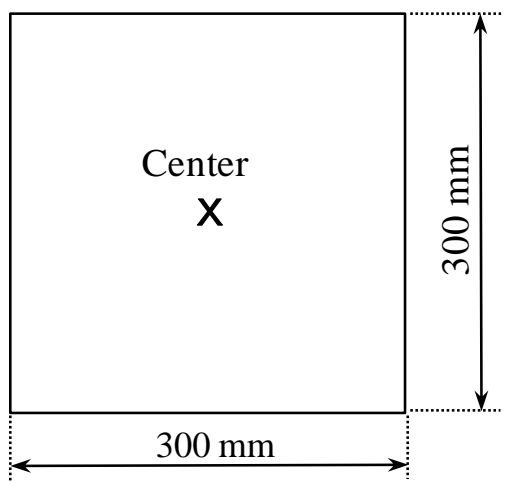

Middle 1 Middle 2

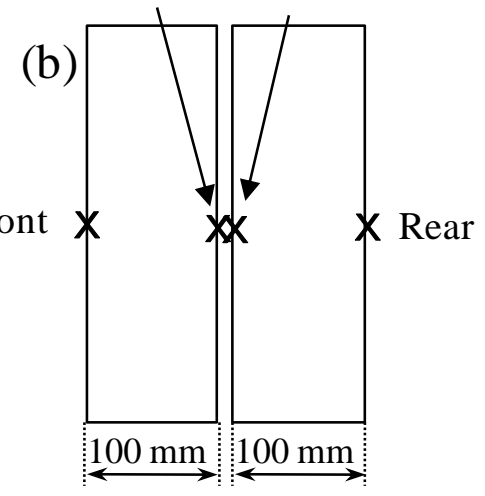


Figure 5. Measurement point of microwave density inside humidifier cavity: (a) Case 1, not installed an element; (b) Case 2, installed one-piece element; and (c) Case 3, installed two-pieces element

(a)

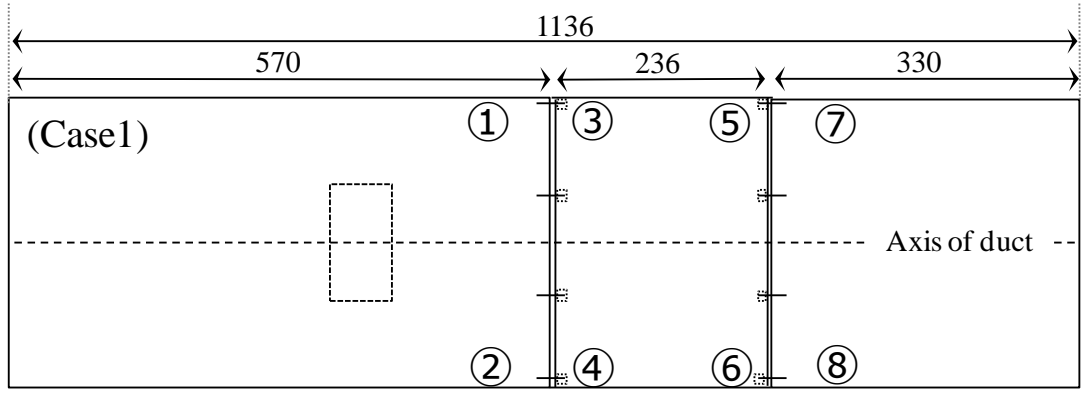

(b)

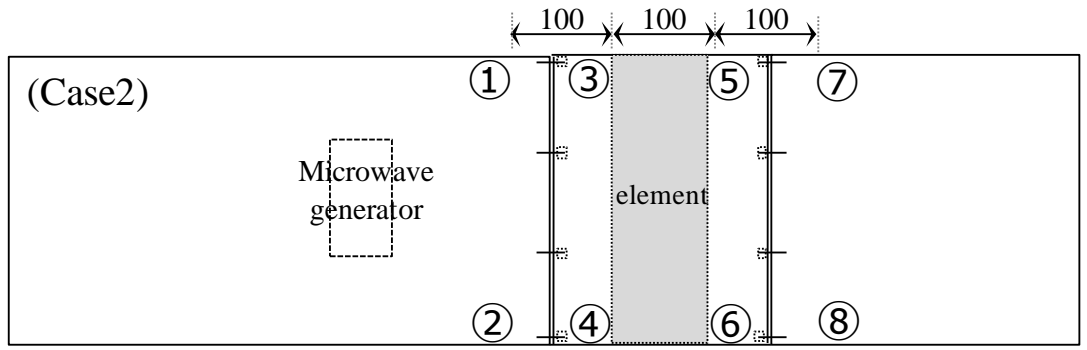

(Case3)

(2)

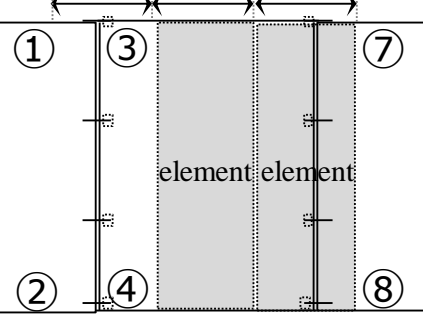

[Unit : mm] 
Figure 6. Temperature changes of the humidifier element upon irradiation: (a) under the operating mode (ventilation, water spraying); and (b) under the non-operating mode
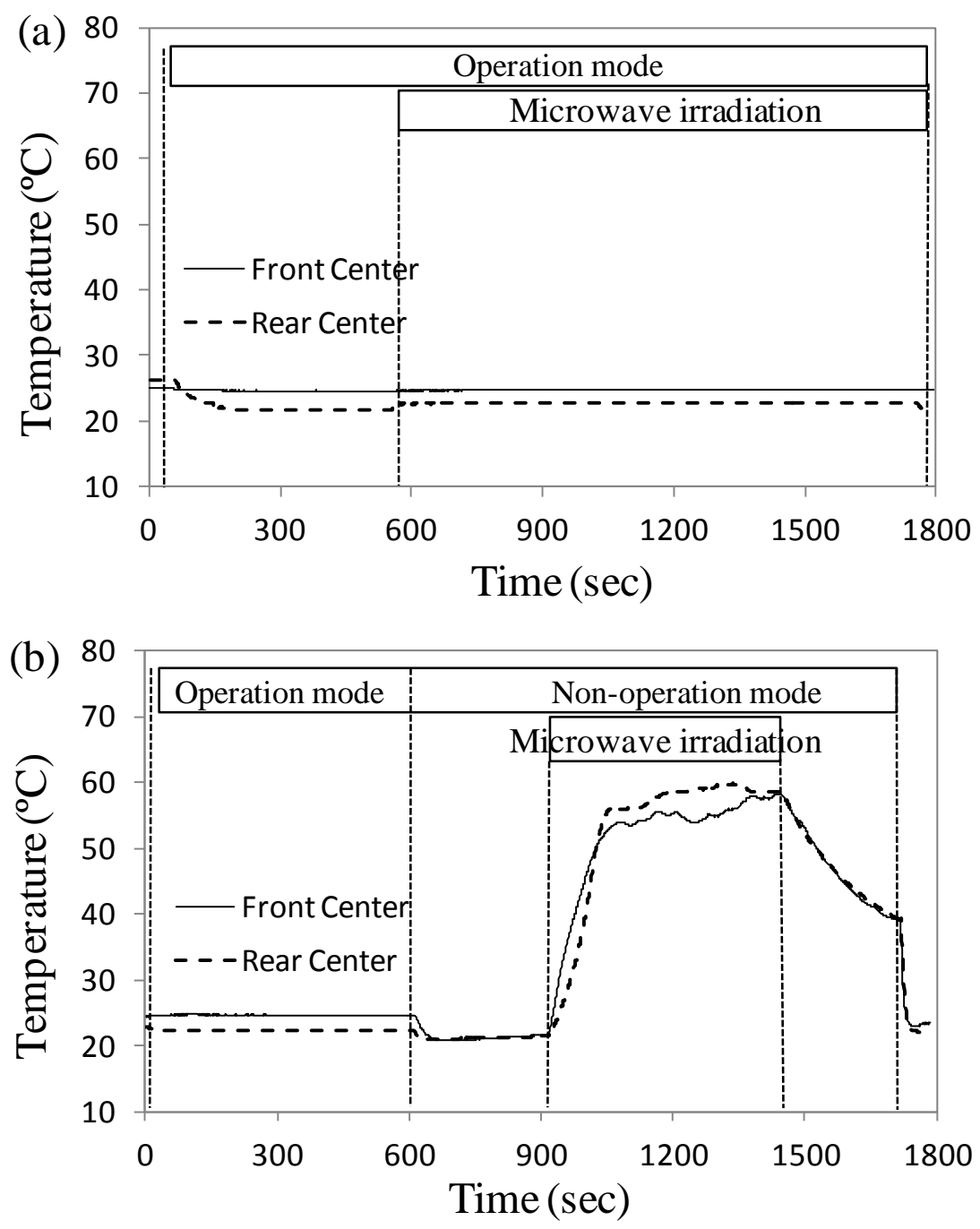
Figure 7. Temperature of the front and rear surfaces at different microwave output powers: (a) front surface; and (b) rear surface
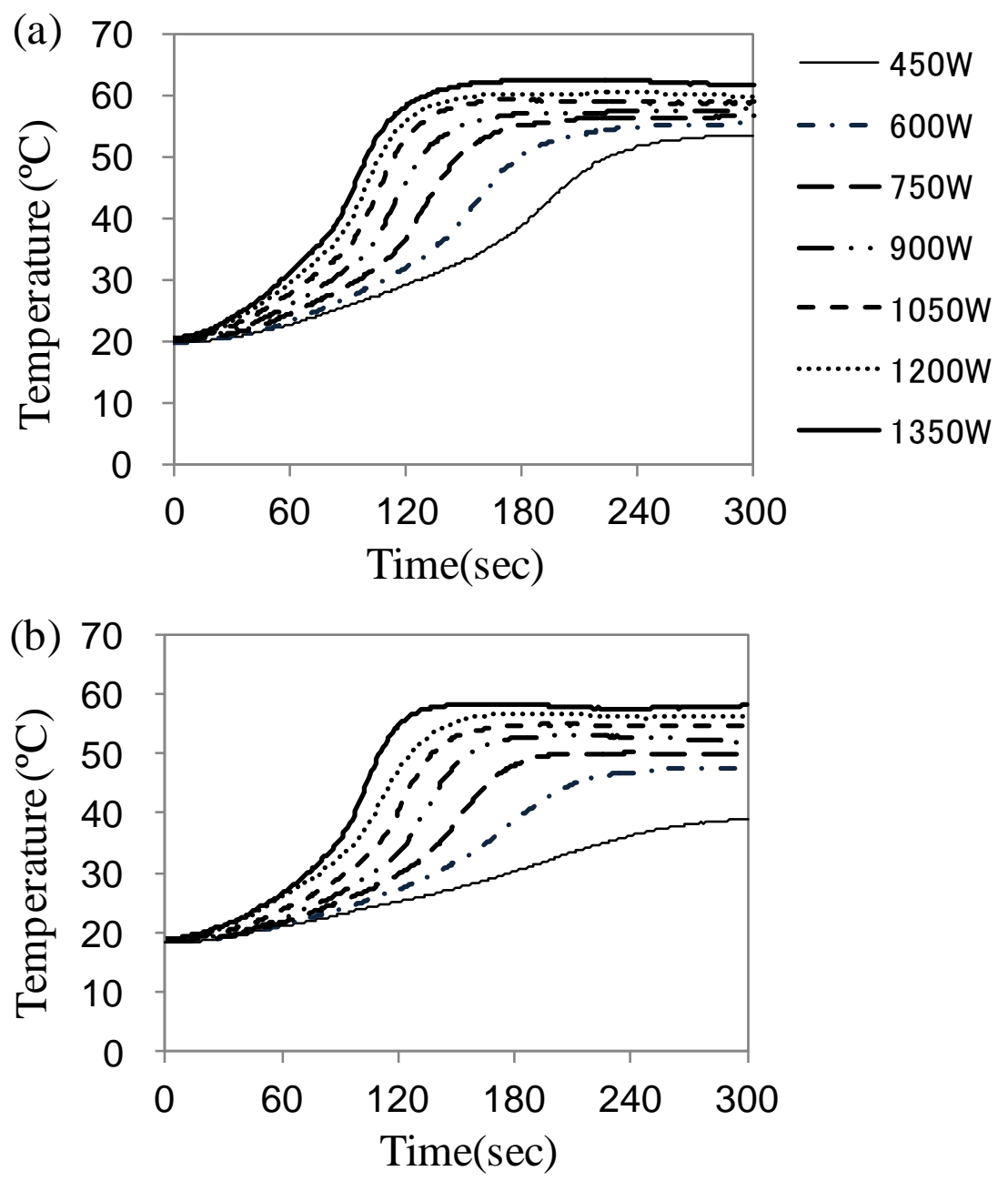
Figure 8. Comparison of the temperature distribution on the element surfaces in the dry condition: (a) temperature change of both surfaces measured in the center; (b) front surface; and (c) rear surface
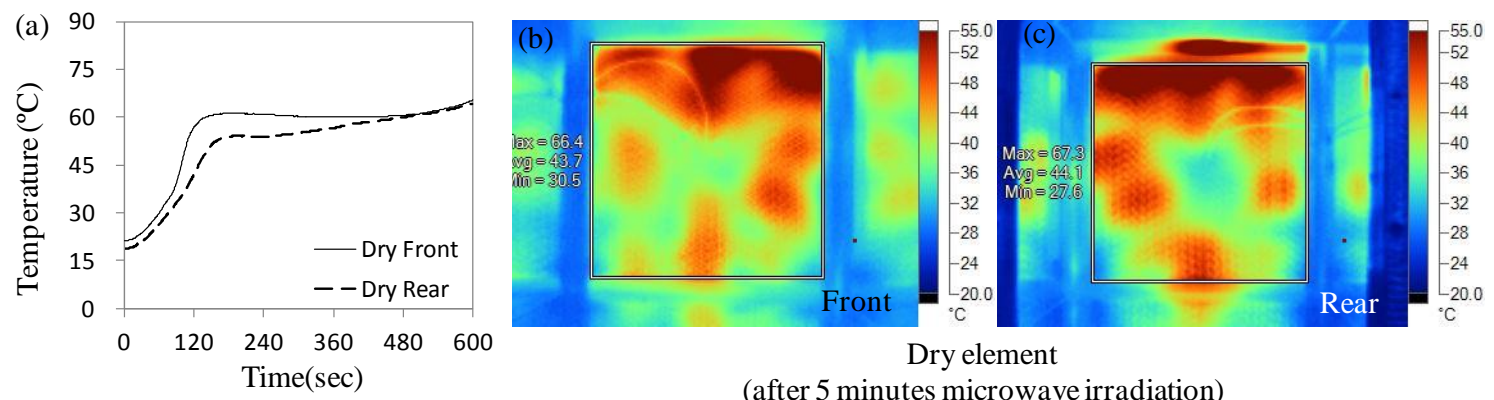

(after 5 minutes microwave irradiation) 
Figure 9. Comparison of the temperature distribution on the element surfaces in the wet condition: (a) temperature change of both surfaces measured in the center; (b) front surface; and (c) rear surface
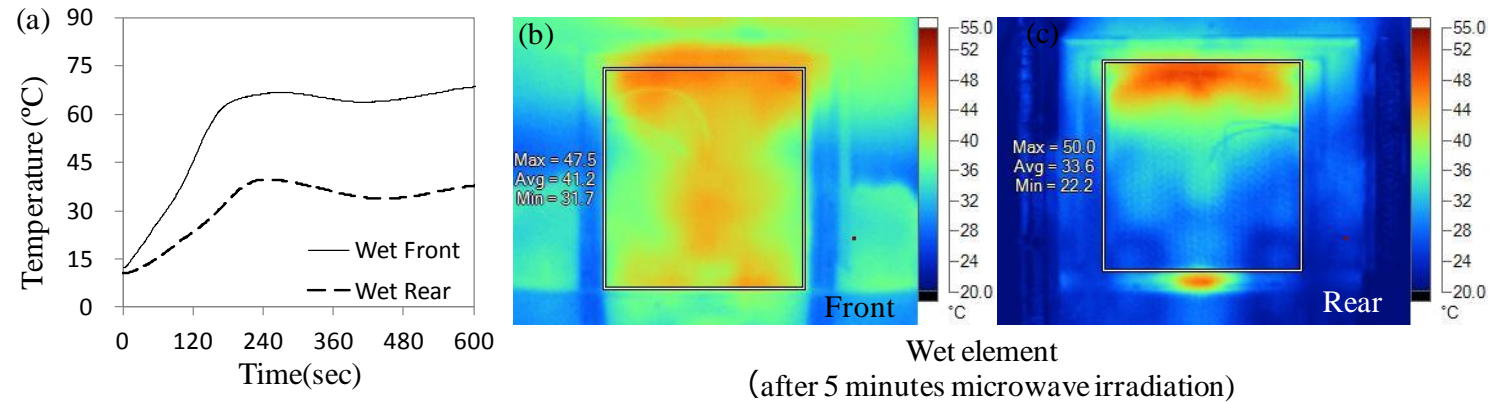
Figure 10. Comparison of the temperature distribution on the two-piece element surfaces in the dry condition: (a) temperature change of both surfaces measured in the center; (b) front surface; and (c) rear surface
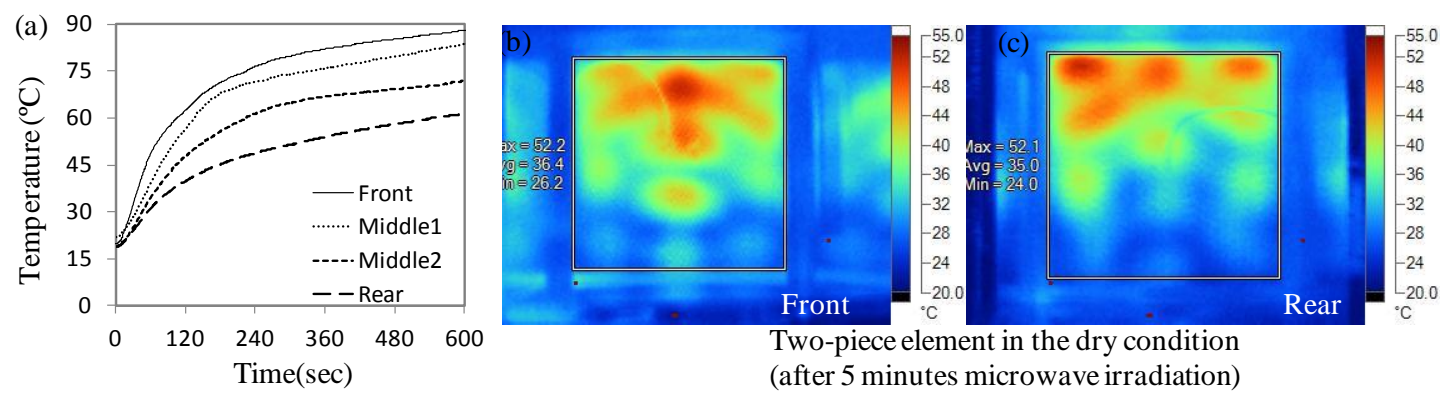